\title{
Tenebrio molitor as an Alternative Model to Analyze the Sporothrix Species Virulence
}

\author{
Nancy E Lozoya-Pérez' \\ Laura C García-Carnero' \\ José A Martínez-Álvarez (D) \\ Iván Martínez-Duncker ${ }^{2}$ \\ Héctor M Mora-Montes iD ${ }^{\prime}$ \\ 'Departamento de Biología, División de \\ Ciencias Naturales y Exactas, Campus \\ Guanajuato, Universidad de Guanajuato, \\ Guanajuato, 36050, México; ${ }^{2}$ Laboratorio \\ de Glicobiología Humana y Diagnóstico \\ Molecular; Centro de Investigación en \\ Dinámica Celular, Instituto de \\ Investigación en Ciencias Básicas \\ y Aplicadas, Universidad Autónoma del \\ Estado de Morelos, Cuernavaca, Morelos, \\ México
}

\begin{abstract}
Background: Sporotrichosis is an increasing threat for humans, affecting mainly skin and subcutaneous tissues but that can cause disseminated infection in immunocompromised patients. Sporothrix schenckii, Sporothrix brasiliensis, and Sporothrix globosa are the main etiological agents of this mycosis, and each species show different virulence levels. The gold standard to assess fungal virulence is the mouse model that is expensive and timeconsuming. Thus, invertebrate models have been reported as an alternative for the evaluation of fungal virulence. Here, we assessed whether Tenebrio molitor larvae could be a new alternative to study Sporothrix spp. virulence.
\end{abstract}

Methods: T. molitor larvae were inoculated with different doses of $S$. schenckii, $S$. brasiliensis, and S. globosa, and animal mortality, cytotoxicity, and immunological parameters were analyzed, including the ability to stimulate immunological priming.

Results: Mortality curves demonstrated that yeast-like cells were the best fungal morphology to kill larvae and showed a similar ranking in virulence than that reported in other animal models, ie, being $S$. brasiliensis and $S$. globosa the species with the highest and lowest virulence, respectively. The usefulness of this model was validated with the analysis of several S. schenckii strains with different virulence degrees, and changes in cytotoxicity, humoral and cellular immunological parameters. Low-virulence strains stimulated low levels of cytotoxicity, phenoloxidase activity, and hemocyte countings, and these immunological cells poorly uptake fungi. Moreover, using recombinant Gp70 from $S$. schenckii immunological priming was stimulated in larvae and this protected against a lethal dose of fungal cells from any of the three species under study.

Conclusion: The study demonstrated that $T$. molitor larvae are an appropriate alternative invertebrate model to analyze the virulence of $S$. schenckii, S. brasiliensis, and S. globosa. Additionally, hemocyte levels, phenoloxidase activity, cytotoxicity, uptake by hemocytes, and immunological priming are biological parameters that can be used to study the Sporothrix-T. molitor interaction.

Keywords: experimental sporotrichosis, fungal infection, host-fungus interplay, hemocytes, phenoloxidase

\section{Introduction}

Infections caused by members of the Sporothrix genus are often benign diseases of the skin and subcutaneous tissues that are distributed worldwide and affect both humans and animals. ${ }^{1-3}$ This infection is traditionally considered as a sapronosis, where decaying vegetal tissues are the natural niche for fungal growth $;{ }^{1}$ however, due to the recent increment in animal sporotrichosis cases, particularly in domestic species, this disease is also now considered as a zoonosis. ${ }^{4-6}$ Most of the cases positively respond to the conventional antifungal therapies or are fixed lesions that

\footnotetext{
Correspondence: Héctor M MoraMontes

Departamento de Biología, División de Ciencias Naturales y Exactas, Campus Guanajuato, Universidad de Guanajuato, Noria Alta s/n, Col. Noria Alta, C.P, Guanajuato, 36050, México

Tel +52 473-7320006 Ext. 8193

Fax +52 473-7320006 Ext. 8153

Email hmora@ugto.mx
} 
are controlled by the host immunity, but there is the risk to develop a life-threatening systemic infection, which in recent years is increasing in frequency, in particular in immunosuppressed patients. $^{7}$

Sporothrix schenckii, Sporothrix brasiliensis, and Sporothrix globosa are the three out of the 51 species classified within the Sporothrix genus that are the etiological agents of most of the animal and human sporotrichosis cases and are grouped within the pathogenic clade of this genus. ${ }^{8} S$. schenckii is historically the first species associated with sporotrichosis and is considered a cosmopolitan species; ${ }^{1,3}$ while $S$. brasiliensis is currently restricted to Brazil and Argentina, ${ }^{1,9,10}$ and associated with epidemic outbreaks of both feline and human sporotrichosis. ${ }^{9,11}$ S. globosa has a broader distribution than $S$. brasiliensis, causing this infectious disease in Asia and to a lesser extent in some parts of America. ${ }^{12-14}$ A bibliographic search about the research performed on sporotrichosis has highlighted that most of this is focused on clinical aspects, treatment, and epidemiology, while basic aspects of the etiological agents are poorly studied. ${ }^{2}$ However, it is well documented that genomic and phenotypical studies of members of the pathogenic clade of Sporothrix spp. can provide valuable information to understand the species-specific traits behind their different virulence degree, geographical distribution, response to antifungal drugs, and sensing by the host immunity. ${ }^{12,15-19}$

The study of virulence is critical in medically relevant fungal species as it helps to understand the foundations of their pathogenicity. Conventionally, this is addressed by mimicking the infection cycle in laboratory animals, which often are not the natural host of the pathogen, and combining fungal genetic manipulation, chemical or antifungal treatments. The murine model of sporotrichosis in mice has been regarded as the gold standard to assess Sporothrix virulence, and subcutaneous, intraperitoneal, and intravenous models of the experimental infection are currently standardized. ${ }^{18,20-29}$ Using these models, the clinically relevant Sporothrix species have been ranked based on the ability to cause damage in the mammalian host, being $S$. globosa the one with the lowest virulence and S. brasiliensis the species associated with the highest mortality rates. ${ }^{18,22,26,28}$ As expected, the $S$. schenckii ability to kill laboratory animals is placed in between these two species. Worthy of mentioning is that the isolation of strains from the three species showing different virulence degrees indicates this ranking is a fungal dynamic trait. ${ }^{18,28,29}$

Even though the murine model has proven to be a valuable tool to analyze Sporothrix spp. virulence, the ethical concerns about the use of mammalians in basic research, along with the specialized facilities to keep animals, and the relatively low number of specimens that can be included in the experimental designs, have limited the research in this area. ${ }^{30}$ Thus, alternative hosts, such as invertebrates, have recently attracted attention as models to study Sporothrix virulence. The wax moth larva Galleria mellonella has been successfully used as a host to study systemic sporotrichosis, ${ }^{31-34}$ and to assess the effect of antifungal drugs on $S$. brasiliensis ability to kill the host. ${ }^{35}$ Also, it has been used to evaluate the stimulation of the immunological priming with the recombinant Gp70 protein ( $\mathrm{rGp} 70)$ from $S$. schenckii and its protection against lethal sporotrichosis. ${ }^{36}$ This invertebrate model is gaining momentum because, differently from mice, the larvae require simple and basic facilities for housing and breeding, large numbers can be included in the experimental setting, strengthening the statistical power, and can be kept at $37^{\circ} \mathrm{C}$, a temperature where dimorphic fungi, such as Sporothrix spp. switch morphology and express temperature-regulated virulence factors that play central roles in the pathogenic process. ${ }^{31,37-39}$ The mealworm Tenebrio molitor larvae are also a popular invertebrate model to study fungal virulence. ${ }^{40}$ Besides sharing all the advantages already listed for G. mellonella, the T. molitor larvae are bigger and therefore, higher volumes of hemolymph can be withdrawn per animal, and higher fungal doses can be used to challenge animals. ${ }^{10}$ Additionally, the immunological response and priming are better characterized in this insect, ${ }^{40,41}$ and thus the contribution of particular immune players is easier to address than in G. mellonella.

Here, to evaluate the use of $T$. molitor larvae as a host for experimental sporotrichosis, we challenged larvae with different doses of conidia and yeast-like cells from S. schenckii, S. brasiliensis, or S. globosa, and evaluated the cytotoxicity and activation of some immunological parameters upon infection. Moreover, we confirmed the usefulness of this model to assess Sporothrix virulence using a set of genetically modified $S$. schenckii strains with virulence profiles already defined in G. mellonella and analyzed the contribution of immunological priming with $\mathrm{rGp} 70$ in the protection against a lethal dose of the pathogen. 


\section{Materials and Methods}

\section{Strains and Culture Media}

The strains used in this study are listed in Table 1. Cells were propagated at $28^{\circ} \mathrm{C}$ in YPD medium $(2 \%[\mathrm{w} / \mathrm{v}]$ gelatin peptone, $1 \%[\mathrm{w} / \mathrm{v}]$ yeast extract, and $3 \%[\mathrm{w} / \mathrm{v}]$ glucose). When a solid medium was required, $2 \%(\mathrm{w} / \mathrm{v})$ agarose was included. For conidia, cells were grown in plates for 7 days at $28^{\circ} \mathrm{C}$ and scrapped out with the assistance of a sterile spreader and PBS. Then, cell concentration was adjusted and immediately used in the inoculation assays. For yeast-like cells, $1 \times 10^{6}$ conidia/ $\mathrm{mL}$ were inoculated in $20 \mathrm{~mL}$ fresh YPD broth, $\mathrm{pH} 7.8$, and incubated in orbital shakers at $37^{\circ} \mathrm{C}$ and $120 \mathrm{rpm}$ for $18 \mathrm{~h}$. Then, an aliquot of $10 \mathrm{~mL}$ was withdrawn from cultures, cells harvested by centrifuging at $2700 \times g$ and $4^{\circ} \mathrm{C}$ for $10 \mathrm{~min}$, washed twice with $\mathrm{PBS}$, and used to inoculate $50 \mathrm{~mL}$ of fresh YPD, $\mathrm{pH} 7.8$, and incubated for 4 days at $37^{\circ} \mathrm{C}$ and $120 \mathrm{rpm} .{ }^{15}$ Even though nearly $100 \%$ of cells underwent dimorphism under these conditions, cells were filtrated in a Buchner filter, ${ }^{42}$ to remove mycelia. The yeast-like cells were suspended in PBS, cell concentration adjusted, and immediately used to inoculate T. molitor larvae.

For heat inactivation, cells were incubated $2 \mathrm{~h}$ at $60^{\circ} \mathrm{C}$, as previously reported. ${ }^{15}$

\section{Ethics Statement}

The use of animals in this study was approved by Universidad de Guanajuato, through the internal Ethics Committee (approval code CIBIUG-P12-2018).

\section{T. molitor Survival Assays}

The T. molitor larvae were purchased from Tenebrios.com (CDMX,México) and were fed ad libitum on bran flour and water, supplemented with apple. For the experiments, $10^{\text {th }}$ $12^{\text {th }}$ instar larvae were used, without evident body injuries or melanization. ${ }^{38}$ Fungal challenges, in $10 \mu \mathrm{L}$ of PBS and loaded in a Hamilton syringe equipped with a 26-gauge needle, were inoculated into the hemocele, piercing at the second or third visible sternite above the legs of the larva, in the ventral portion. ${ }^{38}$ After inoculation, animals were kept in Petri dishes at $37^{\circ} \mathrm{C}$, containing chopped apples to avoid dehydration. ${ }^{31,44}$ The silk on the animal surface was removed as soon as noticed, to delay the transition to the pupal stage. Dead animals were defined as those showing no sign of irritability and extensive body melanization, and shrinking (Figure 1). To assess the animal mortality rate by manipulation and mechanical injuries, animal groups were injected only with PBS. Each experimental group was composed of 30 larvae. The animal groups were under observation for up to 15 days, and live animals at the end of this period, along with those killed by the fungal inocula were decapitated with a sterile scalpel, and the hemolymph used to calculate the colony-forming units (CFUs) by serial dilutions that were incubated on YPD plates, $\mathrm{pH} 4.5$, at $28^{\circ} \mathrm{C}$ for $72 \mathrm{~h}$.

\section{Analysis of Lactate Dehydrogenase and Phenoloxidase Activities, and Hemocyte Levels}

Animal groups, containing ten specimens per group, were challenged with fungal cells as described in the previous

Table I Strains Used in This Work

\begin{tabular}{|c|c|c|c|}
\hline Strain & Organism & Genotype & Reference \\
\hline 1099-18 ATCC MYA 482I & Sporothrix schenckii & Wild-type & 24 \\
\hline 5110 ATCC MYA 4823 & Sporothrix brasiliensis & Wild-type & 24 \\
\hline FMR 9624 & Sporothrix globosa & Wild-type & 43 \\
\hline HSS2 & Sporothrix schenckii & I099-I8 ATCC MYA 482 I transformed with I copy of pBGgHg & 33 \\
\hline HSS3 & Sporothrix schenckii & 1099-I8 ATCC MYA 482I transformed with I copy of pBGgHg & 33 \\
\hline HSS4 & Sporothrix schenckii & 1099-18 ATCC MYA 482 I transformed with I copy of pBGgHg & 33 \\
\hline HSS5 & Sporothrix schenckii & 1099-18 ATCC MYA 482I transformed with 3 copies of pBGgHg & 33 \\
\hline HSS6 & Sporothrix schenckii & 1099-18 ATCC MYA 4821 transformed with 3 copies of pBGgHg & 33 \\
\hline HSS7 & Sporothrix schenckii & I099-18 ATCC MYA 482I transformed with pBGgHg-OCHI & 32 \\
\hline HSS8 & Sporothrix schenckii & 1099-18 ATCC MYA 482I transformed with pBGgHg-OCHI & 32 \\
\hline HSS9 & Sporothrix schenckii & I099-18 ATCC MYA 482I transformed with pBGgHg-OCHI & 32 \\
\hline HSSIO & Sporothrix schenckii & 1099-18 ATCC MYA 482I transformed with pBGgHg-OCHI & 32 \\
\hline HSSII & Sporothrix schenckii & 1099-I8 ATCC MYA 482I transformed with pBGgHg-OCHI & 32 \\
\hline HSSI2 & Sporothrix schenckii & 1099-I8 ATCC MYA 482I transformed with I copy of pBGgHg & 32 \\
\hline HSSI3 & Sporothrix schenckii & 1099-I8 ATCC MYA 482I transformed with I copy of pBGgHg & 32 \\
\hline
\end{tabular}



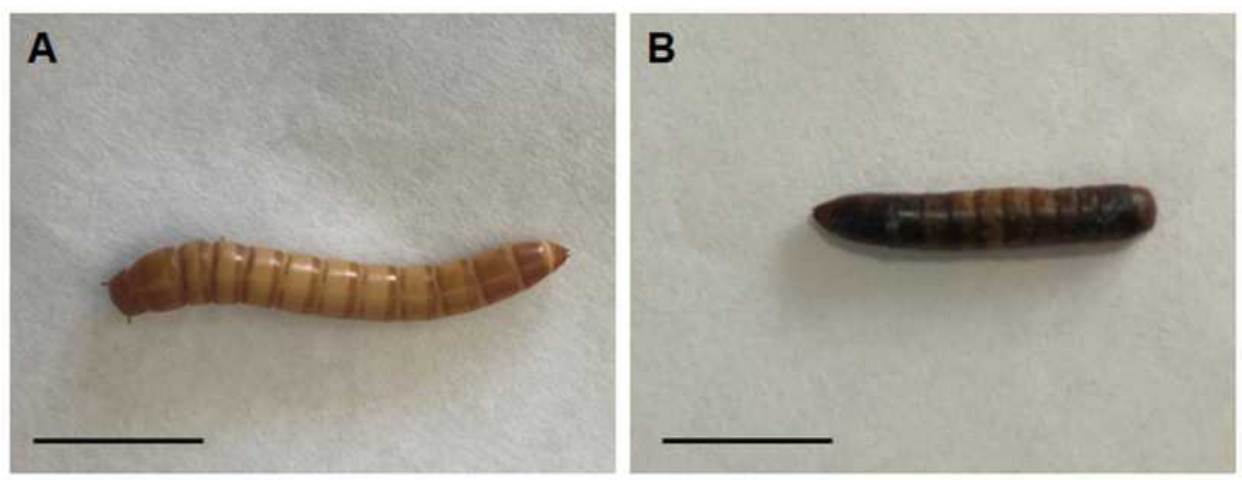

Figure I Representative images of Tenebrio molitor larva before and after interaction with Sporothrix spp. In (A), a healthy larva with no signs of disease. In (B), a dead larva after interaction with Sporothrix cells. Please note the increased melanization and body shrinkage in (B). Scale bar: $\mathrm{I} \mathrm{cm}$.

section and incubated at $37^{\circ} \mathrm{C}$ for $24 \mathrm{~h}$ before decapitation. On average, $20 \mu \mathrm{L}$ of hemolymph were recovered from each larva, in agreement with previous reports, ${ }^{40}$ and were mixed with ice-chilled $60 \mu \mathrm{L}$ of anticoagulant solution $(93 \mathrm{mM}$ $\mathrm{NaCl}, 100 \mathrm{mM}$ glucose, $30 \mathrm{mM}$ trisodium citrate, $26 \mathrm{mM}$ citric acid, $10 \mathrm{mM} \mathrm{Na}{ }_{2}$ EDTA, and $0.1 \mathrm{mM}$ phenylthiourea, $\mathrm{pH} 4.6),{ }^{34}$ to avoid hemolymph clotting. For quantification of enzyme activities, hemolymph was centrifuged at 20,000 $\times \mathrm{g}$ for $10 \mathrm{~min}$, and the cell-free supernatant was saved and the protein concentration quantified with the Pierce BCA Protein Assay (Thermo Fisher Scientific, Waltham, MA, USA). Released lactate dehydrogenase (LDH) was analyzed with the Pierce LDH Cytotoxicity Assay (Thermo Fisher Scientific, Waltham, MA, USA), and using a MultiskanTM FC microplate photometer (Thermo Fisher Scientific, Waltham, MA, USA) with wavelengths set at $490 \mathrm{~nm}$ and $680 \mathrm{~nm}^{45}$ The $100 \% \mathrm{LDH}$ activity was regarded as that quantified in fresh homogenized hemocytes. For phenoloxidase quantification, reactions were performed with $100 \mu \mathrm{g}$ protein and $20 \mathrm{mM}$ 3,4-dihydroxyDL-phenylalanine (Sigma-Aldrich St Louis, MO, USA), and placed in a final volume of $200 \mu \mathrm{L}$ in 96-well microplates. The initial absorbance at $490 \mathrm{~nm}$ was read in a MultiskanTM FC microplate photometer and then reactions were incubated for $30 \mathrm{~min}$ at $37^{\circ} \mathrm{C}$, before reading again the absorbance at the same wavelength. ${ }^{36}$ Phenoloxidase activity was defined as the change in the absorbance at $490 \mathrm{~nm}$ per minute and per $\mu \mathrm{g}$ protein. ${ }^{36}$ Hemocytes were quantified in a hemocytometer, as previously described. ${ }^{36}$

\section{Analysis of Fungal Phagocytosis by T. molitor Hemocytes}

PBS-washed yeast-like cells were incubated with $1 \mathrm{mg} / \mathrm{mL}$ acridine orange (Sigma-Aldrich St Louis, MO, USA) as described elsewhere, ${ }^{46}$ washed twice with PBS, cell concentration adjusted at $3 \times 10^{7}$ yeast-like cells $/ \mathrm{mL}$, placed in six-well plates, and incubated with anticoagulant-treated hemocytes in a hemocyte-yeast ratio of 1:6 in $800 \mu \mathrm{L}$ of DMEM (Sigma-Aldrich, St Louis, MO, USA). ${ }^{34}$ The interactions were incubated for $2 \mathrm{~h}$ at $37^{\circ} \mathrm{C}$ and $5 \%(\mathrm{v} / \mathrm{v}) \mathrm{CO}_{2}$, and then hemocytes were washed twice with cold PBS and suspended in $1.25 \mathrm{mg} / \mathrm{mL}$ trypan blue, used as an external fluorescence quencher. ${ }^{47}$ Samples were analyzed by flow cytometry in a FACSCanto II equipped with a FACSDiva acquisition system (Becton Dickinson, Franklin Lakes, NJ, USA). A total of 25,000 events were collected per sample, gating for hemocyte cells. Fluorescent signals were obtained using the FL1 (green) and FL2 (red) channels, previously compensated with non-stained hemocytes. ${ }^{46,47}$

\section{Immunological Priming}

Groups of 30 animals were injected with $10 \mu \mathrm{L}$ of PBS or the same volume of PBS containing $10 \mu \mathrm{g}, 20 \mu \mathrm{g}, 40 \mu \mathrm{g}, 80 \mu \mathrm{g}$, or $160 \mu \mathrm{g}$ rGp70 produced and purified as described elsewhere. ${ }^{36}$ The protein was LPS free, as tested with the Limulus amebocyte lysate (Sigma, data not shown). Nonetheless, inoculations were conducted in the presence of $5 \mu \mathrm{g} / \mathrm{mL}$ polymyxin $\mathrm{B}$ (Sigma), ${ }^{48}$ including the drug in the PBS, even in the control group. Larvae were kept at $37^{\circ} \mathrm{C}$ for 5 days and then $10 \mu \mathrm{L}$ of PBS or $10 \mu \mathrm{L}$ containing $1 \times 10^{6}$ yeast-like cells were injected into the animal groups. Insects were again kept at $37^{\circ} \mathrm{C}$ and monitored daily for 2 weeks. As a control, mortality in groups exposed only to rGp70 was also assessed.

\section{Statistical Analysis}

Statistical analysis was performed using the GraphPad Prism 6 software. A total of 30 larvae per group were used in the inoculation experiments. Data were plotted in 
Kaplan-Meier survival curves and analyzed using the Log rank test. For other experiments, results were analyzed with the Mann-Whitney $U$-test and expressed as the media \pm standard deviation from three independent experiments performed by duplicate. The statistical significance was set at $P<0.05$ in all cases.

\section{Results}

\section{Sporothrix spp. Kills Tenebrio molitor Larvae in a Dose-Dependent Manner}

Yeast-like cells from the three fungal species were grown as described in the Materials and methods section and used to inoculate T. molitor larvae. In all cases, the killing curves showed a dose-dependent ability of fungal cells to kill the animal populations, with $1 \times 10^{5}$ yeast-like cells associated with higher median survivals, followed by $1 \times 10^{6}$ yeast-like cells, and $1 \times 10^{7}$ cells (Figure $2 \mathrm{~A}$ ). For $S$. schenckii yeastlike cells, the fungal challenges of $1 \times 10^{5}, 1 \times 10^{6}$, and $1 \times 10^{7}$ yeast-like cells generated median survivals of animals of $9.0 \pm 1.0,5.0 \pm 1.2$, and $2.0 \pm 1.0$ days, and $30.0 \pm 3.5 \%$, $6.7 \pm 1.4 \%$ and $0.0 \pm 0.0 \%$ animal population survived after the 15-day observation period, respectively (Figure 2A); while for $S$. brasiliensis, when $1 \times 10^{5}, 1 \times 10^{6}$, and $1 \times 10^{7}$ yeast-like cells were inoculated in the animals, median survivals of $5.0 \pm 0.9,3.0 \pm 1.0$, and $2.0 \pm 0.5$ days were observed, respectively, and no animals survived at the end of the observation period, regardless of the inoculum size (Figure 2A). For S. globosa, challenges of $1 \times 10^{5}, 1 \times 10^{6}$, and $1 \times 10^{7}$ yeast-like cells inoculated into the animals were associated with median survivals of $12.0 \pm 1.1,7.0 \pm 1.4$, and $2.5 \pm 0.7$ days, and $46.7 \pm 6.4 \%, 20.0 \% \pm 4.8 \%$, and 6.7 $\pm 1.4 \%$ of the animal population survived at the end of the observation period, respectively (Figure 2A). When we compared the survival curves generated with the different Sporothrix species but with similar inoculum size, we found that the curves generated with $1 \times 10^{5}$ or $1 \times 10^{6}$ yeast-likes cells were significantly different from each other $(P<0.05)$, but the comparison of the curves generated with $1 \times 10^{7}$ yeast-like cells did not show statistical significance $(P=0.17)$.

For the case of conidia, when larvae were challenged with $1 \times 10^{5}, 1 \times 10^{6}$, and $1 \times 10^{7} \mathrm{~S}$. schenckii cells, median survivals of $>15.0,7.0 \pm 1.5$, and $4.0 \pm 1.1$ days were observed, and $60.0 \pm 10.0 \%, 20.0 \pm 9.1 \%$, and $10.0 \pm$ $8.0 \%$ of the animal population survived, respectively (Figure 2B); while for $S$. brasiliensis cells, the animal median survival was $14.0 \pm 1.4,8.5 \pm 0.9$, and $4.5 \pm 1.5$ days when inoculated with $1 \times 10^{5}, 1 \times 10^{6}$, and $1 \times 10^{7}$ conidia, respectively (Figure $2 \mathrm{~B}$ ). The mortality associated with those fungal inocula was $53.3 \pm 6.7 \%, 76.7 \pm 11.4 \%$, and $86.7 \pm 9.7 \%$, respectively. When larvae were inoculated with S. globosa $1 \times 10^{5}, 1 \times 10^{6}$, and $1 \times 10^{7}$ conidia, the median survival was $>15.0,8.0 \pm 1.1$, and $5.0 \pm 1.6$ days; and $63.3 \pm$ $11.4 \%, 36.7 \pm 9.6 \%$, and $10.0 \pm 6.4 \%$ of the animal populations survived at the end of the 15-day observation period, respectively (Figure $2 \mathrm{~B}$ ). When the survival curves generated with $1 \times 10^{5}$ conidia from the three species under analysis were compared, we did not find any significant difference $(P=0.59)$, and similarly, when the curves generated with
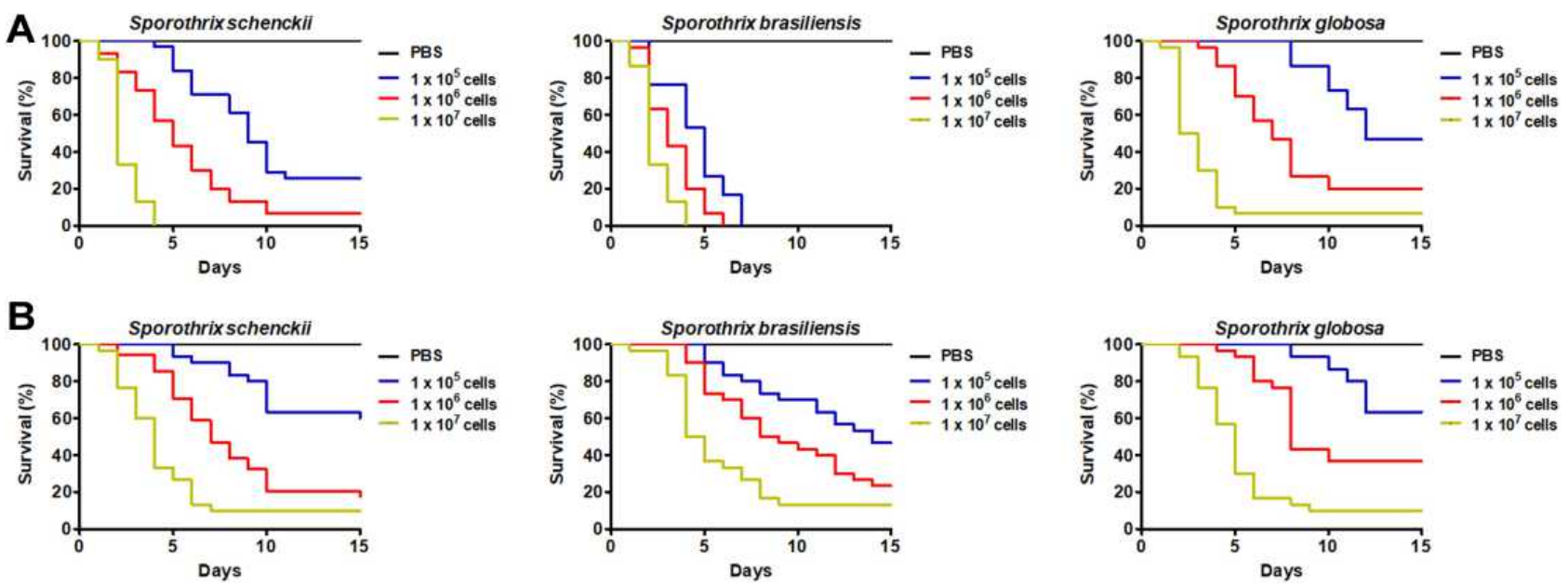

Figure 2 Mortality curves of Tenebrio molitor larvae infected with Sporothrix schenckii, Sporothrix brasiliensis, or Sporothrix globosa. Aliquots of $10 \mu \mathrm{L}$ containing I $\times 10^{5}$, I $\times 10^{6}$, or $1 \times 10^{7}$ of yeast-like cells $(\mathbf{A})$ or conidia (B) from the fungal species under analysis were used to inoculate T. molitor larvae. A total of 30 animals were included in each experimental group, and these were monitored daily to assess mortality, which was defined as lack of irritability and the presence of extensive body melanization. PBS, a control group of 30 animals inoculated only with PBS. 
$1 \times 10^{6}$ conidia were compared to each other $(P=0.056)$ or those generated with $1 \times 10^{7}$ conidia $(P=0.37)$.

For animals inoculated with either yeast-like cells or conidia, the curves were significantly different when compared to those generated with different inocula from the same fungal species $(P<0.05)$, and no dead animal was recorded in the control reactions, where animals were injected only with PBS (Figure 2A and B).

These data suggested that the analyzed inoculum size of conidia is not able to show differences in the animal mortality associated with the different fungal species, nor the $1 \times 10^{7}$ yeast-like cell inoculum, but fungal challenges of $1 \times 10^{5}$ or $1 \times 10^{6}$ yeast-like cells were capable of killing the animal population similarly as reported in mice and $G$. mellonella larvae, keeping the previously reported virulence rank, ie, $S$. brasiliensis as the fastest species to kill the host and $S$. globosa the slowest. Therefore, we continued our analysis only with animals inoculated with either $1 \times 10^{5}$ or $1 \times 10^{6}$ yeastlike cells.

When animals were inoculated with $1 \times 10^{5}$ or $1 \times 10^{6}$ yeastlike cells previously inactivated by heat we did not find any animal killed in the 15-day observation period (data not shown), confirming that the mortality is linked to fungal viability.

Next, to demonstrate the fungal growth within inoculated animals, we quantified the CFUs in infected animals. Similar CFUs were retrieved from animals infected with $1 \times 10^{5}$ yeastlike cells from $S$. schenckii, $S$. brasiliensis, or $S$. globosa, suggesting a similar ability of the three fungal species to adapt to the host milieu (Table 2). As expected, the CFUs quantified in animals infected with $1 \times 10^{6}$ yeast-like cells were higher when compared to those from the groups challenged with $1 \times 10^{5}$ cells (Table 2 ), but again, were similar when the animal groups infected with the three different fungal species under analysis were compared to each other (Table 2). So far, no marker to assess cytotoxicity has been reported in T. molitor. We have previously demonstrated that the measurement of LDH activity in the cell-free hemolymph can be used as a cytotoxicity marker in $G$. mellonella larvae infected with fungal cells, ${ }^{34,44,45}$ and since this enzyme activity has been previously reported in T. molitor hemolymph, ${ }^{49,50}$ along with its putative encoding gene, ${ }^{51}$ we hypothesized that the measurement of this enzyme activity would increase in the infected animals with the Sporothrix spp. yeast-like cells. The LDH activity in the cell-free hemolymph from animals infected with any of the three fungal species was significantly higher than the background measurements obtained in PBS-injected larvae, and there was an LDH activity increment in a dosedependent manner, which was statistically significant for the case of animals infected with $S$. schenckii or $S$. brasiliensis $(P<$ 0.05; Table 2), but not for those where $S$. globosa was used as inoculum ( $P=0.103$; Table 2$)$. Additionally, we observed a differential increment in the cytotoxicity, depending on the fungal species used to inoculate animals, with the highest cytotoxicity associated with animals infected with S. brasiliensis, intermediate quantifications for those injected with $S$. schenckii, and the lowest LDH activities were found in animals infected with $S$. globosa yeast-like cells (Table 2).

Table 2 Colony-Forming Units, Cytotoxicity, Hemocytes Counting, and Phenoloxidase Activity in Tenebrio molitor Inoculated with Sporothrix spp

\begin{tabular}{|c|c|c|c|c|}
\hline Inoculum & Colony-Forming Units $\left(\times 10^{5}\right)^{a}$ & Cytotoxicity (\%) & Hemocytes $\left(\times 10^{6}\right) / \mathrm{mL}^{\mathrm{c}}$ & Phenoloxidase $^{\mathrm{d}}$ \\
\hline $\mathrm{PBS}^{\mathrm{e}}$ & $0.0 \pm 0$ & $8.6 \pm 5.4$ & $3.6 \pm 0.4$ & $0.8 \pm 0.3$ \\
\hline \multicolumn{5}{|l|}{ Sporothrix schenckii } \\
\hline $1 \times 10^{5}$ yeast-like cells & $2.9 \pm 0.6^{*}$ & $37.0 \pm 9.7^{* \neq}$ & $6.8 \pm 0.5^{*} \neq$ & $2.2 \pm 0.3^{*} \neq$ \\
\hline $1 \times 10^{6}$ yeast-like cells & $39.9 \pm 2.9 * \dagger$ & $68.4 \pm 10.7^{*}+\neq$ & $8.2 \pm 0.6 * t \neq$ & $3.3 \pm 0.2 * \neq \neq$ \\
\hline \multicolumn{5}{|l|}{ Sporothrix brasiliensis } \\
\hline $1 \times 10^{5}$ yeast-like cells & $3.1 \pm 0.6^{*}$ & $62.6 \pm 10.3^{*} \neq$ & $8.4 \pm 0.4^{*} \neq$ & $3.2 \pm 0.4^{* \neq}$ \\
\hline $1 \times 10^{6}$ yeast-like cells & $42.8 \pm 3.1 * \dagger$ & $90.5 \pm 9.8 * \dagger \neq$ & $10.9 \pm 0.6 *+\neq$ & $4.8 \pm 0.3^{*} \neq \neq$ \\
\hline \multicolumn{5}{|l|}{ Sporothrix globosa } \\
\hline $1 \times 10^{5}$ yeast-like cells & $3.2 \pm 0.8^{*}$ & $20.5 \pm 6.6^{*} \neq$ & $4.7 \pm 0.4^{*} \neq$ & $1.5 \pm 0.2^{*} \neq$ \\
\hline $1 \times 10^{6}$ yeast-like cells & $44.1 \pm 3.8 * \dagger$ & $34.8 \pm 6.4^{*} \neq$ & $5.2 \pm 0.7^{*} \neq$ & $1.8 \pm 0.4^{*} \neq$ \\
\hline
\end{tabular}

Notes: ${ }^{a}$ Calculated by serial dilutions of the hemolymph and incubating on YPD plates. ${ }^{b}$ Determined by measuring the lactate dehydrogenase activity in the cell-free hemolymph from infected animals. The 100\% refers to enzyme activity quantified from lysed hemocytes. ${ }^{\circ}$ Quantified in the collected hemolymph from infected animals. ${ }^{\mathrm{d}}$ Quantified in the collected hemolymph from infected animals and expressed as the $\Delta_{490 \mathrm{~nm}}$ per min per $\mu \mathrm{g}$ protein. ${ }^{\mathrm{e}}$ Animal group inoculated with PBS. $* P<0.05$ when compared to the animal group inoculated with PBS. $\dagger P<0.05$ when compared with the inoculum size of $1 \times 10^{5}$ yeast-like cells. $¥ P<0.05$ when compared to animals infected with the same inoculum size from the other fungal species under study. 
Hemocytes are cellular effectors of insect immunity that are found in the hemolymph and assist in the control of pathogens, fulfilling a similar task to human phagocytic cells, $;^{37,40,52,53}$ while melanin production, via phenoloxidase activity, is one of the major humoral immune mechanisms against different pathogens, such as bacteria, nematodes, and fungi. ${ }^{34,36,40,44,54-57}$ Changes in both hemocyte levels and phenoloxidase activity have been previously reported in G. mellonella larvae infected with fungal pathogens, such as Candida spp. and Sporothrix spp,,$^{34,36,44,52,58}$ and we hypothesized that variations in the levels of these immune cells could also be observed in Sporothrix-infected T. molitor larvae. We found that both hemocyte and phenoloxidase levels tended to increase in larvae inoculated with any of the three fungal species, and with exception of the animal groups challenged with $S$. globosa yeast-like cells, the increments in both parameters were dependent on the inoculum size (Table 2). Similar to LDH measurements, hemocytes and phenoloxidase levels suffered an increment depending on the Sporothrix species inoculated to T. molitor and followed the same trend, with the highest values observed in the animal group inoculated with $S$. brasiliensis, followed with that challenged with $S$. schenckii, and finally, the group interacting with $S$. globosa, that showed the lowest levels of both hemocytes and phenoloxidase activity (Table 2). Collectively, our data indicate that cytotoxicity, hemocyte levels, and phenoloxidase activity are parameters that change as a consequence of the infection of T. molitor with Sporothrix spp. yeast-like cells.

\section{Interaction of Genetically Modified S. schenckii Strains with Tenebrio Molitor Larvae}

Our group has previously generated genetically modified S. schenckii strains to either validate new tools for the genetic and molecular analysis of this organism, ${ }^{33,59}$ or to assess the contribution of particular genes in the $S$. schenckii-host interaction. ${ }^{32}$ The strains HSS2, HSS3, HSS4, HSS12, and HSS13 harbor one copy of pBGgHg plasmid, which confers resistance to hygromycin $\mathrm{B}$ and expresses the green fluorescent protein; while strains HSS5 andHSS6 contain three copies of this plasmid integrated into the genome. ${ }^{32,33}$ Nonetheless, the seven strains displayed a phenotype similar to the parental strain ATCC MYA 4821, including a similar ability to kill $G$. mellonella larvae. ${ }^{32,33}$ Strains HSS7-HSS11 were transformed with the plasmid $\mathrm{pBGgHg}-\mathrm{OCH1}$, and as consequence, the OCHI gene that encodes for the a1,6-mannosyltransferase that initiates the elaboration of the $N$-linked glycan outer chain was silenced in different degrees, affecting the ability of the fungal cells to kill G. mellonella larvae. ${ }^{32}$ Thus, we tested whether T. molitor larvae inoculated with these strains were killed at a similar rate as that reported when G. mellonella was used.

The median survivals of T. molitor larvae challenged with yeast-like cells of the different strains are shown in Figure 3. The wild-type (WT) strain, along with strains HSS2-HSS6 and HSS12 and HSS13 showed similar median survivals, which significantly varied when the inoculum sizes varied from $1 \times 10^{5}$ to $1 \times 10^{6}$ cells $(P<0.05$ in all cases; Figure 3$)$. Animals inoculated with strain HSS7, which previously showed an intermediate $\mathrm{OCH} 1$ silencing, ${ }^{32}$ showed a median survival higher than the WT control strain when both inoculum sizes were compared (Figure 3), suggesting virulence attenuation as previously documented in G. mellonella. ${ }^{32}$ Finally, the animal groups inoculated with strains HSS8-HSS11 showed a significant increment in the median survivals when compared to both WT and HSS7 strains (Figure 3), suggesting an avirulent phenotype, as reported in G. mellonella larvae. ${ }^{32}$ We also explored the changes in cytotoxicity, hemocyte levels, and phenoloxidase activity associated with the inoculation of these fungal strains in T. molitor. As expected, the three parameters showed modification in a dose-dependent manner, when compared the inocula of $1 \times 10^{5}$ and $1 \times 10^{6}$ cells (Figure 3), and in all cases, these differences were statistically significant $(P<$ 0.05 in all cases). For cytotoxicity, hemocyte levels, and phenoloxidase activity, the animal groups inoculated with WT, HSS2-HHS6, HSS12, or HSS13 showed similar levels, but animals infected with strain HSS7 showed lower levels of the three parameters under analysis (Figure 3). Animal groups infected with the avirulent strains (HSS8-HSS11) showed even lower and significant levels in cytotoxicity, hemocyte levels, and phenoloxidase activity than the WT or HSS7 strains (Figure 3). Interestingly, these parameters were higher $(P<0.05$ in all cases) in these strains, when compared to the control group inoculated only with PBS (Figure 3). Collectively, these data suggest that $T$. molitor larvae can reproduce the mortality associated with genetically modified S. schenckii strains, previously generated in a systemic model of sporotrichosis in G. mellonella. Moreover, they also stress that physiological parameters such as cytotoxicity, hemocyte levels, and phenoloxidase activity are influenced by the Sporothrix virulence. 

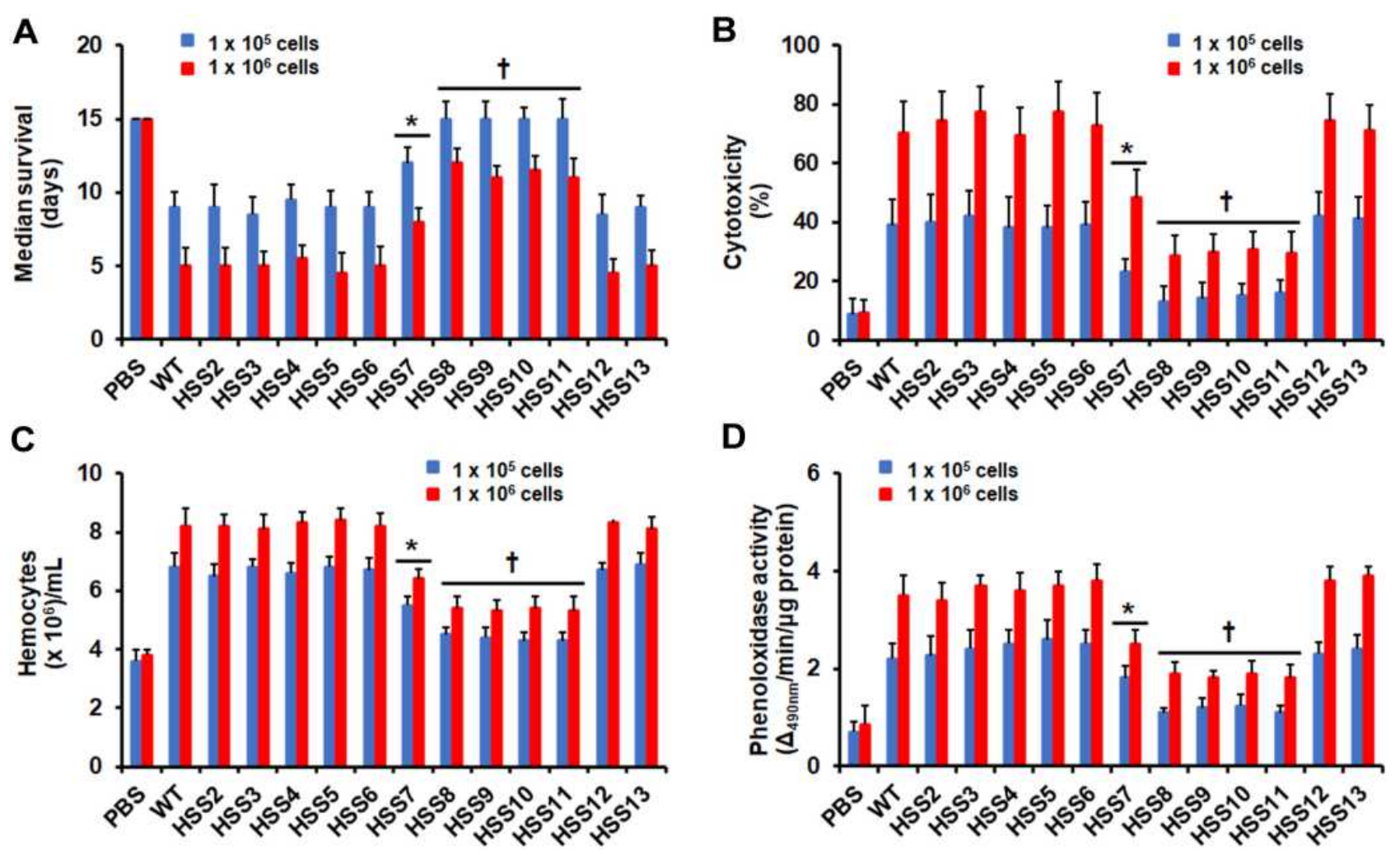

Figure 3 Interaction of Tenebrio molitor larvae with genetically modified Sporothrix schenckii strains. Animal groups, containing 30 individuals per group, were inoculated with either $1 \times 10^{5}$ or $1 \times 10^{6}$ yeast-like cells of different S. schenckii strains, and killing charts were generated using Kaplan-Meier survival curves and analyzed using the Log rank test. From these, the median survival of animals was calculated (A). Alternatively, animal groups were challenged with the fungal doses, incubated at $37^{\circ} \mathrm{C}$ for 24 $\mathrm{h}$ hemolymph collected and used to quantify cytotoxicity (B), hemocytes (C), or phenoloxidase activity (D). In (B), the I00\% cytotoxicity refers to lactate dehydrogenase activity quantified from lysed hemocytes. PBS, control group where animals were inoculated only with PBS. $* P<0.05$, when compared with values generated in animals inoculated with other fungal strains. $\dagger P<0.05$, when compared to HSS7 and the other fungal strains.

\section{Analysis of Sporothrix spp. Yeast-Like Cells Uptake by T. molitor Hemocytes}

We next evaluated the ability of insect hemocytes to uptake yeast-like cells of the strains under analysis. Hemocytes from healthy animals were incubated for $2 \mathrm{~h}$ at $37^{\circ} \mathrm{C}$ using a hemocyte-yeast-like cell ratio of 1:6, as previously performed with hemocytes from G. mellonella. ${ }^{34}$ Since the insect cells are inspected by flow cytometry, it is possible to sort three cell populations that are interacting with yeastlike cells: those that are predominantly emitting green fluorescence, indicating the fungal cells are at the beginning of the phagocytosis or attached to the cell surface, which is defined here as the early stage of phagocytosis; cells that are emitting both green and red fluorescences, indicative of cell internalization and beginning of endosome acidification, and referred here as the intermediate stage of phagocytosis, and lastly, a group of cells emitting predominantly red fluorescence, indicative of acidification of the phagolysosome, and thus, regarded as cells in the late stage of phagocytosis. ${ }^{32}$ Our results showed that there were no changes in the number of hemocytes interacting with any of the three fungal species in the early stage of the process (Figure 4), but there were lower numbers of cells interacting with $S$. brasiliensis yeast-like cells at the intermediate and late stages of phagocytosis when compared with the systems were $S$. globosa or $S$. schenckii cells were included (Figure 4). For the case of $S$. globosa, hemocytes showed the highest numbers of cells interacting with these yeast-like cells and were significantly different when compared with the other two species (Figure 4). When the ability of the insect cells to uptake fungal cells from the different S. schenckii cells was analyzed, we found that WT, HSS2HSS7, HSS12, and HSS13 strains showed similar levels of cells interacting in the three stages of the process, but strains where $\mathrm{OCH1}$ was fully silenced, named HSS8-HSS11 strains, showed increments in the cell numbers at the early stage of the phagocytic process and lower levels for both the intermediate and late stages, suggesting an affectation of the 


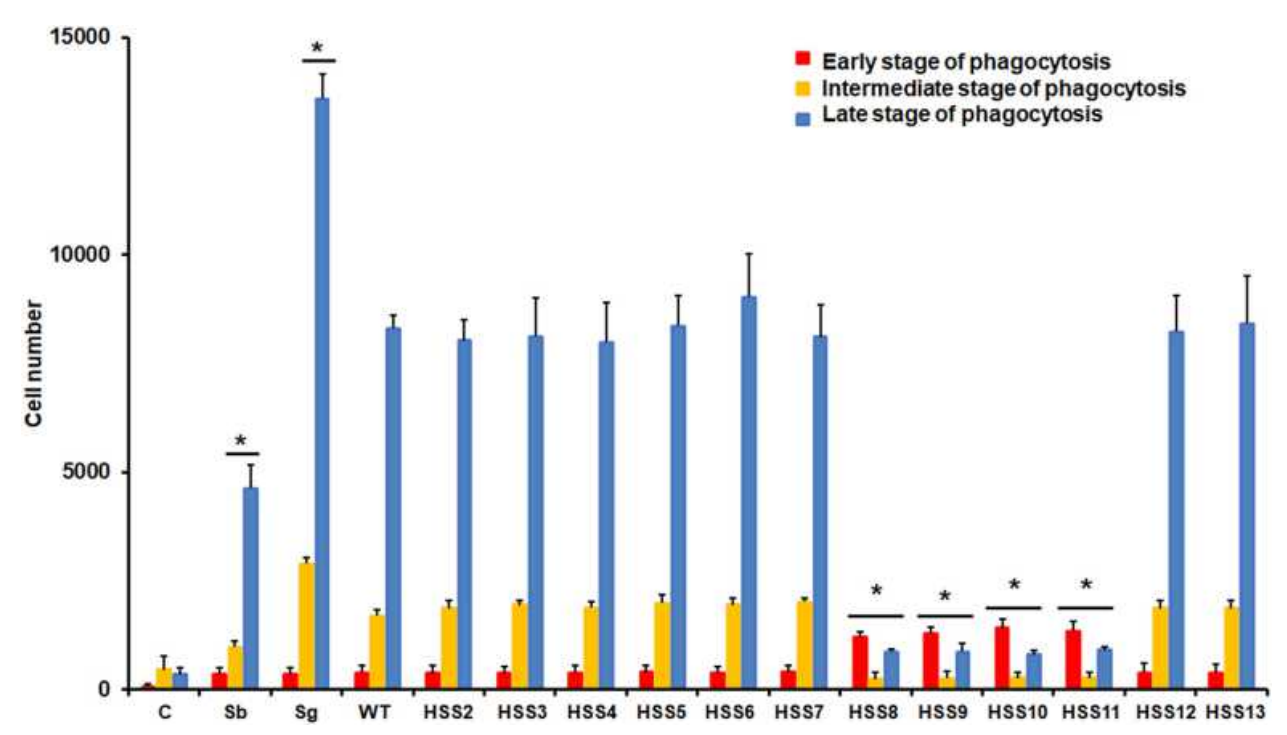

Figure 4 Analysis of phagocytosis of yeast-like cells from Sporothrix schenckii, Sporothrix brasiliensis, or Sporothrix globosa by Tenebrio molitor hemocytes. Fungal cells were stained with Acridine orange and incubated with hemocytes at a hemocyte:yeast ratio of $1: 6$, for 2 hours at $37^{\circ} \mathrm{C}$. Hemocytes were gated by FACS and 25,000 cells were counted per sample. Results represent hemocytes interacting with at least one fluorescent fungal cell. Hemocytes interacting with green yeast cells are regarded as cells in the early stage of phagocytosis, cells interacting with green and red yeast-like cells were considered to be in an intermediate stage of phagocytosis, and hemocytes interacting with red yeast-like cells are classified as in the late stage of phagocytosis. C, control reactions of hemocytes without interaction with fungal cells; Sb, Sporothrix brasiliensis; Sg, Sporothrix globosa; WT, strain 1099-18 ATCC MYA 482I. * $P<0.05$ when compared to WT strain.

phagocytic process of these strains, as already reported when interacting with primary human monocyte-derived macrophages. $^{32}$

\section{Immunological Priming in Tenebrio molitor with rGp70}

We have previously reported that inoculation of $\mathrm{rGp} 70$ protein from $S$. schenckii triggers immunological priming in $G$. mellonella larvae and this protects animals against a lethal fungal inoculum. ${ }^{36}$ Since this immune adaptation has been already reported in T. molitor, ${ }^{60,61}$ we hypothesized the recombinant protein could also be capable of stimulating this immune response. Larvae were inoculated with different doses of recombinant protein and 5 days later, sacrificed to analyze both hemocytes and phenoloxidase levels. Both parameters did not suffer significant variations upon inoculation of 10 or $20 \mu \mathrm{g}$ rGp70, but when a dose of $40 \mu \mathrm{g}$ rGp70 was administered both hemocyte concentration and phenoloxidase activity were significantly higher than untreated larvae (Table 3). An increased dose of either 80 or $160 \mu \mathrm{g}$ rGp70 had a positive effect on both parameters being higher than those quantified in animals inoculated with $40 \mu \mathrm{g}$ of recombinant protein (Table 3 ). In parallel experiments, the animals were under observation for two weeks upon inoculation of the recombinant proteins, and no dead animal was observed (data not shown). Thus, it is possible to suggest the rGp70 at a dose between $40-160 \mu \mathrm{g}$ is capable of stimulating both cellular and humoral components of this insect's immunity. To assess the impact of these changes in the T. molitor ability to survive a lethal dose of fungal cells, animals were inoculated with $1 \times 10^{6}$ yeast-like cells from $S$. schenckii on the fifth day after administration of rGp70, and survival observed for the next 15 days. The median survival of animals inoculated with 0 or 10 $\mu \mathrm{g}$ of recombinant protein was $5.0 \pm 1.0$ days and this

Table 3 Hemocytes Counting and Phenoloxidase Activity in Tenebrio molitor Inoculated with Recombinant Gp70 from Sporothrix schenckii

\begin{tabular}{|c|c|c|}
\hline Inoculum & Hemocytes $\left(\times 10^{6}\right) / \mathrm{mL}^{\mathrm{a}}$ & Phenoloxidase $^{b}$ \\
\hline No inoculation & $3.1 \pm 0.4$ & $0.6 \pm 0.2$ \\
\hline$+0 \mu \mathrm{g} r \mathrm{rp} 70^{\mathrm{c}}$ & $3.3 \pm 0.4$ & $0.6 \pm 0.3$ \\
\hline$+10 \mu g$ rGp70 & $3.6 \pm 0.6$ & $0.5 \pm 0.2$ \\
\hline$+20 \mu \mathrm{g}$ rGp70 & $3.5 \pm 0.4$ & $0.7 \pm 0.4$ \\
\hline$+40 \mu \mathrm{g}$ rGp70 & $8.0 \pm 0.7^{*}$ & $2.2 \pm 0.5^{*}$ \\
\hline + 80 нg rGp70 & $10.5 \pm 0.4^{*} \dagger$ & $3.8 \pm 0.4^{*} \dagger$ \\
\hline$+160 \mu \mathrm{g} \mathrm{rGp70}$ & $10.1 \pm 0.5^{*} \dagger$ & $4.1 \pm 0.3^{*} \dagger$ \\
\hline
\end{tabular}

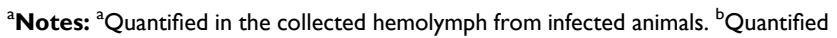
in the collected hemolymph from infected animals and expressed as the $\Delta_{490 \mathrm{~nm}}$ per min per $\mu \mathrm{g}$ protein. 'Animal group inoculated with PBS added with $5 \mu \mathrm{g} / \mathrm{mL}$ polymyxin B. $* P<0.05$, when compared to the animal group inoculated with PBS, added with $5 \mu \mathrm{g} / \mathrm{mL}$ polymyxin $\mathrm{B}$. $\dagger P<0.05$ when compared with the animal group inoculated with $40 \mu \mathrm{g} / \mathrm{mL}$ recombinant Gp70.

Abbreviation: rGp70, recombinant Gp70. 
changed, although not significantly $(P=0.58)$, increasing to $6.0 \pm 1.0$ in the animal group where $20 \mu \mathrm{g} \mathrm{rGp} 70$ were administered (Figure 5A). However, when $40 \mu \mathrm{g}$ rGp70 were inoculated to larvae, the median survival incremented to $10 \pm 0.5$ days and $47.5 \pm 9.0 \%$ of the animal population survived at the end of the observation period (Figure 5A). The inoculation of either 80 or 160 $\mu \mathrm{g} \mathrm{rGp70}$ protected most of the animal population, with $94.0 \pm 6.0 \%$ and $90.0 \pm 8.0 \%$ of survival at the end of the observation, respectively (Figure 5A). When a similar experiment was conducted with either S. brasiliensis or S. globosa yeast-like cells, results were similar: 10 or $20 \mu \mathrm{g}$ rGp70 previously inoculated to animal groups did not affect the mortality associated with these fungal species but $40 \mu \mathrm{g}$ rGp70 positively affected the animal survival (Figure 5A). For the case of S. brasiliensis, the median survival of the animal group without inoculation of rGp70 was $3.0 \pm 0.5$ and this changed to $8.0 \pm 1.5$ days upon administration of $40 \mu \mathrm{g}$ recombinant protein $(P<0.05)$. The change in the survival rate was from $0 \%$ in the animal group without treatment with the protein to $39.0 \pm 7.0 \%$ after administration of $40 \mu \mathrm{g}$ of this $(P<0.05)$. Similarly, for animals infected with $S$. globosa, the median survival changed from $7.0 \pm 1.0$ to $11.5 \pm 1.5$ when compared animals with no pretreatment and pretreated with $40 \mu \mathrm{g}$ rGp70; and the survival changed from $13.3 \pm 6.7 \%$ to
$47.5 \pm 9.4 \%(P<0.05)$, respectively. For the case of doses of 80 and $160 \mu \mathrm{g}$ rGp70, they showed a similar trend like that observed in the animal groups challenged with S. schenckii and protected most of the animal population challenged with either $S$. brasiliensis or S. globosa (Figure 5A). To assess whether this increment in the survival stimulated by the inoculation of rGp70 was due to an increased ability to kill fungal cells, the fungal CFUs were determined in the animal groups. Results showed in Figure 5B showed that CFUs did not significantly change in the animal groups inoculated with 10 or $20 \mu \mathrm{g}$ rGP70, but there was a significant reduction in the fungal load in animals treated with $40 \mu \mathrm{g}$ rGp70 and this was even lower in insects treated with 80 or $160 \mu \mathrm{g}$ rGp70 (Figure 5B). This trend was observed in the three systems challenged with the different Sporothrix species under study (Figure $5 \mathrm{~B})$. In agreement with this observation, the cytotoxicity associated with the fungal inoculations was dependent on the concentration of recombinant protein inoculated, with the highest cytotoxicity values observed in the animal groups inoculated with $0-20 \mu \mathrm{g}$ rGp70 and the lowest with $80-160 \mu \mathrm{g} \mathrm{rGp70}$ (Figure 5C). Again, the same trend was observed in the animal groups challenged with S. schenckii, S. brasiliensis or S. globosa. Therefore, collectively, these data suggest that immunological priming upon inoculation of $\mathrm{rGp} 70$ occurs in

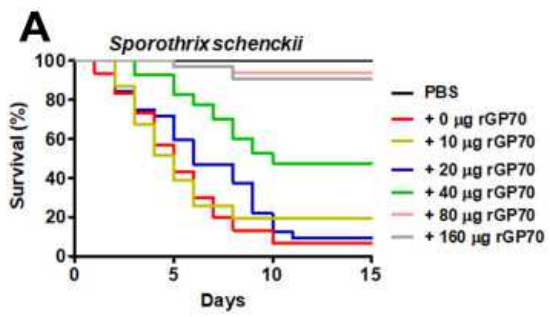

B
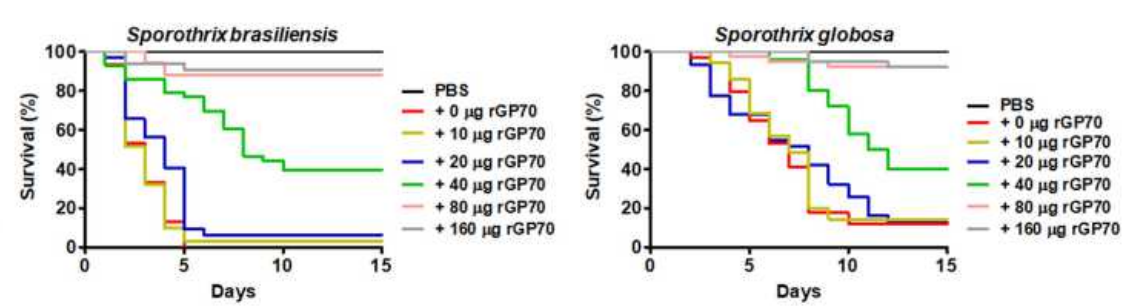

C

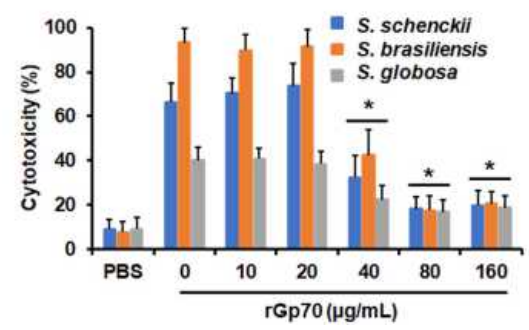

Figure 5 Preinoculation of recombinant Gp70 protects Tenebrio molitor larvae from a lethal dose of Sporothrix spp. In (A), animal groups, containing 30 individuals per group, were inoculated with the indicated dose of recombinant Gp70 ( $\mathrm{rGp} 70)$ from S. schenckii and five days later were challenged with $1 \times 10^{6}$ yeast-like cells and mortality monitored daily. The hemolymph of these animals was recovered and used to quantify the colony-forming units (B) or the activity of lactate dehydrogenase in the cell-free hemolymph, which is regarded here as cytotoxicity (C). The 100\% cytotoxicity refers to the enzyme activity quantified from lysed hemocytes. PBS, animal group inoculated only with PBS. The group inoculated with $0 \mu \mathrm{g}$ rGp70 refers to animals inoculated with PBS $+5 \mu \mathrm{g} / \mathrm{mL}$ polymyxin B. $* P<0.05$, when compared with the animal group incubated with $0 \mu \mathrm{g}$ rGp70. 
T. molitor and this protects against a lethal dose of fungal cells from any of the three fungal species analyzed here.

\section{Discussion}

The increased development of molecular tools to study fungal cells has paved the way to analyze the genetic, biochemical, and metabolic foundations of several fungal processes, including pathogenesis and virulence. ${ }^{62}$ Indeed, nowadays, for most of the pathogenic organisms we are capable of questioning the relevance of a gene, protein, or metabolic pathway during the interaction with the host, and this is constantly requesting to increase the number of laboratory animals to be enrolled in such experimental settings. Despite the vigilance and fulfillment of all ethical considerations, the recent trend in research is to discourage the use of vertebrate animals and to substitute them with an invertebrate model organism when possible. ${ }^{30,37}$ This has fueled up the generation of alternative invertebrate models to study fungal pathogenesis. Thus far, T. molitor larvae have been used to assess the virulence of entomopathogenic fungi like Metarhizium robertsii, ${ }^{63}$ Metarhizium brunneum, ${ }^{64}$ and Beauveria bassiana $;{ }^{65}$ and human pathogens such as Candida albicans, Cryptococcus neoformans, ${ }^{38}$ Fonsecaea pedrosoi, and Fonsecaea monophora. ${ }^{66}$ The results showed here clearly demonstrated that this model is also useful to assess the virulence of S. schenckii, S. brasiliensis, and S. globosa expanding the fungal species repertoire that can be analyzed in these larvae. More importantly, our results showed the virulence of the three species analyzed was ranked in a similar way than previously reported in G. mellonella and mice, being $S$. brasiliensis the most virulent species and $S$. globosa the one associated with the lesser host damage upon inoculation. One limitation of this study though is the inclusion of only one clinical isolate per species, and more of these should be included to assess the model robustness.

In our study, we did not include germlings or hypha because these cell morphologies are unlikely to begin the infective process, which is thought to start when conidia or yeast-like cells from exposed lessons are implanted in healthy tissues. ${ }^{1-3}$ It was previously demonstrated that inoculation of conidia into G. mellonella larvae did not replicate the Sporothrix spp. virulence that was previously ranked using the murine model, ${ }^{34}$ which is in agreement with our observations here, using $T$. molitor. The S. schenckii and S. brasiliensis cell walls have been previously characterized in both conidia and yeast-like cells, and have shown morphology-dependent changes that could be behind the differential interactions with the host cells. ${ }^{15}$

Using G. mellonella larva, it has been previously reported that highly virulent Sporothrix strains, with short median survival times of the animal groups, were associated with increased levels of circulating hemocytes, while animals infected with highly virulent Candida species and strains stimulated a decrement in the levels of circulating immune cells. ${ }^{34,44,52}$ It has been proposed that as a response to the aggressiveness of the fungal strain, the insect invests resources in the generation of more hemocytes to counterattack the damage caused by the pathogen, but since the interactions are performed at $37^{\circ} \mathrm{C}$, Candida cells undergo filamentation and these can pierce the hemocyte membrane, promoting the loss of cell viability and providing an explanation to the reduction of these circulating cells, ${ }^{41}$ a fact that is unlikely to occur in insects infected with Sporothrix cells that keep the yeast-like morphology at $37^{\circ} \mathrm{C} .{ }^{15}$ Since our results are similar to that already reported for the G. mellonella-Sporothrix interaction, it is possible to suggest a similar explanation to the increased hemocyte levels in animals inoculated with virulent Sporothrix strains.

The phenoloxidase activity is essential to catalyze the phenol oxidation to quinones that non-enzymatically polymerizes forming melanin. ${ }^{57}$ It has been previously demonstrated that melanin production via conversion of the prophenoloxidase to phenoloxidase by Spätzleprocessing enzyme is required to control infections caused by Mycoplasma pulmonis and Escherichia coli. ${ }^{55,57,67}$ For the case of T. molitor-fungal cell interaction, its contribution to immunity has only been investigated when interacting with M. robertsii. ${ }^{63}$ To the best of our knowledge, here we report for the first time the modulation of this enzyme activity during the interaction of $T$. molitor with medically relevant fungal species and found that it is a humoral component that responds against the fungal cells and as part of the immunological priming, similarly to G. mellonella ${ }^{34,36}$ Antimicrobial peptides are other humoral components that participate in the T. molitor immune response against fungal pathogens. ${ }^{68,69}$ Thus, one limitation of our study and a future direction is to assess the contribution of these immune effectors against Sporothrix spp.

The quantification of cytotoxicity, measured as the LDH activity in the cell-free hemolymph, showed a good negative correlation with the aggressivity of the fungal cells, increasing when the median survivals were short and reduced when 
virulence was attenuated, as in the case of the strains where $O C H 1$ was silenced. It is possible to suggest that this parameter by itself or in combination with others, could be early indicators of the fungal virulence when analyzed in T. molitor larvae, as previously proposed in G. mellonella. ${ }^{44}$

The rGp70 protective role against a lethal dose of S. schenckii was previously reported in G. mellonella and this was achieved via stimulation of immunological elicitors after inoculation of the recombinant protein. ${ }^{36}$ Here, we demonstrate that this can also be replicated in T. molitor larvae and therefore, it is a suitable model to study immunological priming stimulated by fungal components. Interestingly, the recombinant protein based on the amino acid sequence of the $S$. schenckii protein was also capable of protecting larva from a lethal infection with $S$. brasiliensis and S. globosa cells after administration of doses of $40 \mu \mathrm{g}$ or higher. This can be explained by the high similarity among the Gp70 proteins from the three fungal species, which is $91 \%$ and $90 \%$ when compared the protein from S. schenckii with the one from S. brasiliensis or S. globosa, respectively. In line with the observations, a cross-reactivity of antiGp70 monoclonal antibodies was reported with proteins from the three species, stressing the similarity in terms of the primary structure. ${ }^{70}$ Thus, it is feasible to conceive that the recent strategies to control sporotrichosis, based on the Gp70 from S. brasiliensis ${ }^{71}$ or S. globosa ${ }^{72}$ could have a wider application against these three Sporothrix species.

\section{Conclusion}

In conclusion, our study demonstrated that $T$. molitor larvae are an appropriate alternative invertebrate model to analyze the virulence of $S$. schenckii, S. brasiliensis, and S. globosa. Additionally, hemocyte levels, phenoloxidase activity, cytotoxicity, uptake by hemocytes, and immunological priming are biological parameters that can be used to study the Sporothrix-T. molitor interaction.

\section{Acknowledgments}

We acknowledge the technical assistance of Luz A. LópezRamírez (Universidad de Guanajuato) during data acquisition. This work was supported by Consejo Nacional de Ciencia y Tecnología (ref. FC 2015-02-834 and CF-20196380), and Red Temática Glicociencia en Salud (CONACYT-México).

\section{Author Contributions}

All authors made a significant contribution to the work reported, whether that is in the conception, study design, execution, acquisition of data, analysis, and interpretation, or in all these areas; took part in drafting, revising or critically reviewing the article; gave final approval of the version to be published; have agreed on the journal to which the article has been submitted; and agree to be accountable for all aspects of the work.

\section{Disclosure}

The authors declare no conflict of interests.

\section{References}

1. Lopes-Bezerra LM, Mora-Montes HM, Zhang Y, et al. Sporotrichosis between 1898 and 2017: the evolution of knowledge on a changeable disease and on emerging etiological agents. Med Mycol. 2018;56 (suppl_1):126-143.

2. Mora-Montes HM, Dantas Ada S, Trujillo-Esquivel E, de Souza Baptista AR, Lopes-Bezerra LM. Current progress in the biology of members of the Sporothrix schenckii complex following the genomic era. FEMS Yeast Res. 2015;15:6.

3. López-Romero E, Reyes-Montes Mdel R, Pérez-Torres A, et al. Sporothrix schenckii complex and sporotrichosis, an emerging health problem. Future Microbiol. 2011;6(1):85-102.

4. Rossow JA, Queiroz-Telles F, Caceres DH, et al. A one health approach to combatting Sporothrix brasiliensis: narrative review of an emerging zoonotic fungal pathogen in South America. J Fungi (Basel). 2020;6:4.

5. Han HS, Kano R. Feline sporotrichosis in Asia. Braz J Microbiol. 2020.

6. Rodrigues AM, Della Terra PP, Gremião ID, Pereira SA, OrofinoCosta R, de Camargo ZP. The threat of emerging and re-emerging pathogenic Sporothrix species. Mycopathologia. 2020;185 (5):813-842.

7. Queiroz-Telles F, Buccheri R, Benard G. Sporotrichosis in immunocompromised hosts. J Fungi (Basel). 2019;5(1):8.

8. de Beer ZW, Duong TA, Wingfield MJ. The divorce of Sporothrix and Ophiostoma: solution to a problematic relationship. Stud Mycol. 2016;83:165-191.

9. Rodrigues AM, de Hoog GS, de Camargo ZP. Sporothrix species causing outbreaks in animals and humans driven by animal-animal transmission. PLoS Pathog. 2016;12(7):e1005638.

10. Etchecopaz AN, Lanza N, Toscanini MA, et al. Sporotrichosis caused by Sporothrix brasiliensis in Argentina: case report, molecular identification and in vitro susceptibility pattern to antifungal drugs. J Mycol Med. 2020;30(1):100908.

11. Gremião ID, Miranda LH, Reis EG, Rodrigues AM, Pereira SA. Zoonotic epidemic of sporotrichosis: cat to human transmission. PLoS Pathog. 2017;13(1):e1006077.

12. Moussa TAA, Kadasa NMS, Al Zahrani HS, et al. Origin and distribution of Sporothrix globosa causing sapronoses in Asia. $J$ Med Microbiol. 2017;66(5):560-569.

13. Chakrabarti A, Bonifaz A, Gutierrez-Galhardo MC, Mochizuki T, Li S. Global epidemiology of sporotrichosis. Med Mycol. 2015;53 (1):3-14.

14. Camacho E, León-Navarro I, Rodríguez-Brito S, Mendoza M, Niño-Vega GA. Molecular epidemiology of human sporotrichosis in Venezuela reveals high frequency of Sporothrix globosa. BMC Infect Dis. 2015;15:94. 
15. Martinez-Alvarez JA, Perez-Garcia LA, Mellado-Mojica E, et al. Sporothrix schenckii sensu stricto and Sporothrix brasiliensis are differentially recognized by human peripheral blood mononuclear cells. Front Microbiol. 2017;8:843.

16. Teixeira MM, de Almeida LG, Kubitschek-Barreira P, et al. Comparative genomics of the major fungal agents of human and animal sporotrichosis: sporothrix schenckii and Sporothrix brasiliensis. BMC Genomics. 2014;15:943.

17. Silva-Bailão MG, de Sousa Lima P, Evangelista de Oliveira MM, et al. Comparative proteomics in the three major human pathogenic species of the genus Sporothrix. Microbes Infect. 2020.

18. Fernandes GF, dos Santos PO, Rodrigues AM, Sasaki AA, Burger E, de Camargo ZP. Characterization of virulence profile, protein secretion and immunogenicity of different Sporothrix schenckii sensu stricto isolates compared with $S$. globosa and $S$. brasiliensis species. Virulence. 2013;4(3):241-249.

19. Huang L, Gao W, Giosa D, et al. Whole-genome sequencing and in silico analysis of two strains of Sporothrix globosa. Genome Biol Evol. 2016;8(11):3292-3296.

20. Oliveira MME, Almeida-Paes R, Corrêa-Moreira D, et al. A case of sporotrichosis caused by different Sporothrix brasiliensis strains: mycological, molecular, and virulence analyses. Mem Inst Oswaldo Cruz. 2019;114:e190260-e190260.

21. Batista-Duharte A, Téllez-Martínez D, Aparecida Jellmayer J, et al. Repeated exposition to mercury (ii) chloride enhances susceptibility to S. schenckii sensu stricto infection in mice. J Fingi (Basel). 2018;4(2):64.

22. Della Terra PP, Rodrigues AM, Fernandes GF, Nishikaku AS, Burger E, de Camargo ZP. Exploring virulence and immunogenicity in the emerging pathogen Sporothrix brasiliensis. PLoS Negl Trop Dis. 2017;11(8):e0005903-e0005903.

23. Cruz Choappa R, Pérez Gaete S, Rodríguez Badilla V, Vieille Oyarzo P, Opazo Sanchez H. Virulence of Sporothrix globosa in murine models. Rev Argent Microbiol. 2016;48(3):196-199.

24. Castro RA, Kubitschek-Barreira PH, Teixeira PA, et al. Differences in cell morphometry, cell wall topography and gp70 expression correlate with the virulence of Sporothrix brasiliensis clinical isolates. PLoS One. 2013;8(10):e75656.

25. Fernandes KSS, Mathews HL, Bezerra LML. Differences in virulence of Sporothrix schenckii conidia related to culture conditions and cell-wall components. J Med Microbiol. 1999;48(2):195-203.

26. Almeida-Paes R, De oliveira LC, Oliveira MME, GutierrezGalhardo MC, Nosanchuk JD, Zancopé-Oliveira RM. Phenotypic characteristics associated with virulence of clinical isolates from the Sporothrix complex. Biomed Res Int. 2015;2015:212308.

27. Kong X, Xiao T, Lin J, Wang Y, Chen HD. Relationships among genotypes, virulence and clinical forms of Sporothrix schenckii infection. Clin Microbiol Infect. 2006;12(11):1077-1081.

28. Arrillaga-Moncrieff I, Capilla J, Mayayo E, et al. Different virulence levels of the species of Sporothrix in a murine model. Clin Microbiol Infect. 2009;15(7):651-655.

29. Teixeira PA, De castro RA, Nascimento RC, et al. Cell surface expression of adhesins for fibronectin correlates with virulence in Sporothrix Schenckii Microbiology. 2009;155(Pt 11):3730-3738.

30. Jacobsen ID. Galleria mellonella as a model host to study virulence of Candida. Virulence. 2014;5(2):237-239.

31. Clavijo-Giraldo DM, Matinez-Alvarez JA, Lopes-Bezerra LM, et al. Analysis of Sporothrix schenckii sensu stricto and Sporothrix brasiliensis virulence in Galleria mellonella. J Microbiol Methods. 2016;122:73-77.

32. Lozoya-Perez NE, Casas-Flores S, de Almeida JRF, et al. Silencing of $O C H 1$ unveils the role of Sporothrix schenckii $N$-linked glycans during the host-fungus interaction. Infect Drug Resist. 2019;12:67-85.

33. Lozoya-Perez NE, Casas-Flores S, Martinez-Alvarez JA, et al. Generation of Sporothrix schenckii mutants expressing the green fluorescent protein suitable for the study of host-fungus interactions. Fungal Biol. 2018;122(10):1023-1030.
34. Lozoya-Perez NE, Clavijo-Giraldo DM, Martinez-Duncker I, et al. Influences of the culturing media in the virulence and cell wall of Sporothrix schenckii, Sporothrix brasiliensis, and Sporothrix globosa. J Fungi (Basel). 2020;6:4.

35. Passos JS, Martino LC, Dartora VFC, Araujo GLB, Ishida K, Lopes LB. Development, skin targeting and antifungal efficacy of topical lipid nanoparticles containing itraconazole. Eur j Pharm Sci. 2020;149:105296.

36. Martinez-Alvarez JA, Garcia-Carnero LC, Kubitschek-Barreira PH, et al. Analysis of some immunogenic properties of the recombinant Sporothrix schenckii Gp70 expressed in Escherichia coli. Future Microbiol. 2019;14:397-410.

37. Desalermos A, Fuchs BB, Mylonakis E. Selecting an invertebrate model host for the study of fungal pathogenesis. PLOS Pathog. 2012;8(2):e1002451.

38. de Souza PC, Morey AT, Castanheira GM, et al. Tenebrio molitor (Coleoptera: tenebrionidae) as an alternative host to study fungal infections. J Microbiol Methods. 2015;118:182-186.

39. Tamez-Castrellon AK, Romeo O, Garcia-Carnero LC, Lozoya-Perez NE, Mora-Montes HM. Virulence factors in Sporothrix schenckii, one of the causative agents of sporotrichosis. Curr Protein Pept Sci. 2020;21(3):295-312.

40. Canteri de Souza P, Custodio Caloni C, Wilson D, Sergio Almeida R. An invertebrate host to study fungal infections, mycotoxins and antifungal drugs: tenebrio molitor. J Fungi (Basel). 2018;4:4.

41. Vigneron A, Jehan C, Rigaud T, Moret Y. Immune defenses of a beneficial pest: the mealworm beetle, Tenebrio molitor. Front Physiol. 2019;10:138.

42. Mora-Montes HM, Robledo-Ortiz CI, Gonzalez-Sanchez LC, LopezEsparza A, Lopez-Romero E, Flores-Carreon A. Purification and biochemical characterisation of endoplasmic reticulum alpha1,2-mannosidase from Sporothrix Schenckiil. Mem Inst Oswaldo Cruz. 2010;105(1):79-85.

43. Madrid H, Cano J, Gene J, Bonifaz A, Toriello C, Guarro J. Sporothrix globosa, a pathogenic fungus with widespread geographical distribution. Rev Iberoam Micol. 2009;26(3):218-222.

44. Garcia-Carnero LC, Clavijo-Giraldo DM, Gomez-Gaviria M, et al. Early virulence predictors during the Candida species-Galleria mellonella Interaction. J Fungi (Basel). 2020;6:3.

45. Gomez-Gaviria M, Lozoya-Perez NE, Staniszewska M, Franco B, Nino-Vega GA, Mora-Montes HM. Loss of Kex2 affects the Candida albicans cell wall and interaction with innate immune cells. J Fungi (Basel). 2020;6:2.

46. Hernandez-Chavez MJ, Franco B, Clavijo-Giraldo DM, Hernandez NV, Estrada-Mata E, Mora-Montes HM. Role of protein phosphomannosylation in the Candida tropicalis-macrophage interaction. FEMS Yeast Res. 2018;18:5.

47. Gonzalez-Hernandez RJ, Jin K, Hernandez-Chavez MJ, et al. Phosphomannosylation and the functional analysis of the extended Candida albicans MNN4-like gene family. Front Microbiol. 2017;8:2156.

48. Navarro-Arias MJ, Defosse TA, Dementhon K, et al. Disruption of protein mannosylation affects candida guilliermondii cell wall, immune sensing, and virulence. Front Microbiol. 2016;7:1951.

49. Ludwig D, Barsa MC. Activity of dehydrogenase enzymes during the metamorphosis of the mealworm, Tenebrio molitor Linnaeus. Ann Entomol Soc Am. 1958;51(3):311-314.

50. Ito T, Fraenkel G. The effect of nitrogen starvation on Tenebrio molitor L. J Insect Physiol. 1966;12(7):803-817.

51. Eriksson T, Andere AA, Kelstrup H, Emery VJ, Picard CJ. The yellow mealworm (Tenebrio molitor) genome: a resource for the emerging insects as food and feed industry. J Insects Food Feed. 2020;6(5):445-455.

52. Bergin D, Brennan M, Kavanagh K. Fluctuations in haemocyte density and microbial load may be used as indicators of fungal pathogenicity in larvae of Galleria mellonella. Microb Infect. 2003;5(15):1389-1395. 
53. Mesa-Arango AC, Forastiero A, Bernal-Martinez L, CuencaEstrella M, Mellado E, Zaragoza O. The non-mammalian host Galleria mellonella can be used to study the virulence of the fungal pathogen Candida tropicalis and the efficacy of antifungal drugs during infection by this pathogenic yeast. Med Mycol. 2013;51(5):461-472.

54. Roy MC, Kim Y. Tolerance of the mealworm beetle, Tenebrio molitor, to an entomopathogenic nematode, Steinernema feltiae, at two infection foci, the intestine and the hemocoel. J Invertebr Pathol. 2020;174:107428.

55. Lim S, Yun HK, Kang KM, Lee BL, Won R, Lee IH. Interactions between Mycoplasma pulmonis and immune systems in the mealworm beetle, Tenebrio molitor. Insect Biochem Mol Biol. 2019;114:103231.

56. Valtonen TM, Viitaniemi H, Rantala MJ. Copulation enhances resistance against an entomopathogenic fungus in the mealworm beetle. Tenebrio Molitor Parasitology. 2010;137(6):985-989.

57. Kan H, Kim CH, Kwon HM, et al. Molecular control of phenoloxidase-induced melanin synthesis in an insect. J Biol Chem. 2008;283(37):25316-25323.

58. Kavanagh K, Sheehan G. The use of Galleria mellonella larvae to identify novel antimicrobial agents against fungal species of medical interest. J Fungi (Basel). 2018;4:3.

59. Tamez-Castrellon AK, Romo-Lucio R, Martinez-Duncker I, MoraMontes HM. Generation of a synthetic binary plasmid that confers resistance to nourseothricin for genetic engineering of Sporothrix schenckii. Plasmid. 2018;100:1-5.

60. Moret Y. "Trans-generational immune priming": specific enhancement of the antimicrobial immune response in the mealworm beetle Tenebrio Molitor. Proc Biol Sci. 2006;273(1592):1399-1405.

61. Dhinaut J, Chogne M, Moret Y. Immune priming specificity within and across generations reveals the range of pathogens affecting evolution of immunity in an insect. J Anim Ecol. 2018;87 (2):448-463.

62. Krappmann S. CRISPR-Cas9, the new kid on the block of fungal molecular biology. Med Mycol. 2017;55(1):16-23.
63. Rantala MJ, Dubovskiy IM, Pölkki M, Krama T, Contreras-Garduño J, Krams IA. Effect of juvenile hormone on resistance against entomopathogenic fungus Metarhizium robertsii differs between sexes. J Fungi (Basel). 2020;6(4):298.

64. Bharadwaj A, Stafford KC 3rd. Potential of Tenebrio molitor (Coleoptera: tenebrionidae) as a bioassay probe for Metarhizium brunneum (Hypocreales: clavicipitaceae) activity against Ixodes scapularis (Acari: ixodidae). J Econ Entomol. 2011;104(6):2095-2098.

65. Jirakkakul J, Roytrakul S, Srisuksam C, et al. Culture degeneration in conidia of Beauveria bassiana and virulence determinants by proteomics. Fungal Biol. 2018;122(2-3):156-171.

66. Fornari G, Gomes RR, Degenhardt-Goldbach J, et al. A model for trans-kingdom pathogenicity in Fonsecaea agents of human chromoblastomycosis. Front Microbiol. 2018;9:2211.

67. Kim MH, Joo CH, Cho MY, et al. Bacterial-injection-induced syntheses of N-beta-alanyldopamine and Dopa decarboxylase in the hemolymph of coleopteran insect, Tenebrio molitor larvae. Eur j Biochem. 2000;267(9):2599-2608.

68. Keshavarz M, Jo YH, Park KB, et al. TmDorX2 positively regulates antimicrobial peptides in Tenebrio molitor gut, fat body, and hemocytes in response to bacterial and fungal infection. Sci Rep. 2019;9:16878.

69. Keshavarz M, Jo YH, Edosa TT, Bae YM, Han YS. TmPGRP-SA regulates antimicrobial response to bacteria and fungi in the fat body and gut of Tenebrio molitor. Int J Mol Sci. 2020;21(6):2113.

70. Rodrigues AM, Kubitschek-Barreira PH, Fernandes GF, de Almeida SR, Lopes-Bezerra LM, de Camargo ZP. Immunoproteomic analysis reveals a convergent humoral response signature in the Sporothrix schenckii complex. J Proteomics. 2015;115:8-22.

71. de Almeida JRF, Jannuzzi GP, Kaihami GH, Breda LCD, Ferreira KS, de Almeida SR. An immunoproteomic approach revealing peptides from Sporothrix brasiliensis that induce a cellular immune response in subcutaneous sporotrichosis. Sci Rep. 2018;8(1):4192.

72. Chen F, Jiang R, Wang Y, et al. Recombinant phage elicits protective immune response against systemic $S$. globosa infection in mouse model. Sci Rep. 2017;7:42024.
Infection and Drug Resistance

\section{Publish your work in this journal}

Infection and Drug Resistance is an international, peer-reviewed openaccess journal that focuses on the optimal treatment of infection (bacterial, fungal and viral) and the development and institution of preventive strategies to minimize the development and spread of resistance. The journal is specifically concerned with the epidemiology of

\section{Dovepress}

antibiotic resistance and the mechanisms of resistance development and diffusion in both hospitals and the community. The manuscript management system is completely online and includes a very quick and fair peerreview system, which is all easy to use. Visit http://www.dovepress.com/ testimonials.php to read real quotes from published authors. 